\title{
Engineering Quality Systems: Cost of Quality
}

\author{
Dadi He \\ School of Economics, Peking University \\ 18 Hexi Road, Guangxi, China 545007 \\ E-mail: dadi.he@sgmw.com.cn
}

\begin{abstract}
The text mainly discusses the quality control and management concept. The quality cost was divided into different stages and each of them is related to the others. The competent analysis of the quality cost should help to find out the best way to minimize the quality cost.
\end{abstract}

Keywords: Quality matnagement, Cost, Reduce

\section{Introduction}

According to survey over the last 40 years, in western companies quality costs account for between $5 \%$ and $40 \%$ of turnover. (Parker, 1995, P5). That is wide area for management to make an improvement to get more money. Therefore how to reduce the quality cost to reach a better quality level is a key point for a successes company. A competitive product based on a balance between quality and cost factors is the principal goal of management. The target of quality management is achieving the quality standard in a minimal cost. The concept of quality cost itself is a difficult one. This concept was developed with TQM practise since 1960'. Based on Dale's opinions, (1999), the quality cost may be regarded as a criterion of quality performance - but only if valid comparisons can be made between different sets of cost data. In general, the cost quality is the total of the cost incurred for quality control process and the lost of product defect. We should make a competent analysis of the quality cost to find out a best way to minimal the quality cost. In TQM system, the quality controls are happen in all level. That means we can reduce quality cost in everywhere of an organization. Before we discuss how to achieve greatest profit by reducing the quality cost, let us discuss the quality cost based on two models.

The first model is the so-called P-A-F model first presented by Feigenbaum. He point out that the necessary quality activities will incur costs that may be separated into prevention cost, appraisal costs and failure cost,

1) Prevention cost. There costs mostly occur for quality system implementation and design. When we want to achieve a high quality lever, the prevention cost is always high.

2) Appraise cost. There costs mostly occur for quality inspects process. If the stability of quality is high, the appraise cost should be low.

3) Failure cost. These costs mostly occur when the product or service fail to reach design quality standards. We got to spend money to rework or scrap material. If this products or services transfer to the consumer, we also need to compensate the loss of consumer. The worse thing is we may lose the good will. If the stability of quality is high, the appraise cost should be low.

Failure costs can be further split into internal and external failure. Obviously, the external failure cost is more serious than internal failures cost because the product fails to reach the quality standards but are not detected until after the consumer give a feedback on it. This will impact on reputation of company, which impinges directly on future outlook for sales.

But it can be argued that makes the separation of prevention costs very difficult. All the management cost related to quality management could no be looked as prevention costs. Therefore the so-called "process cost model" described in the revised British Standard 6143-1(1992) is a better method for applying quality to a company. It uses process modelling to simplify classification. According to the British Standard, the cost of quality has been separated into the cost of conformance (COC) and the cost of non- conformance (CONC): $\quad \mathrm{COQ}=\mathrm{COC}+$ CONC

The cost of conformance (COC) is the process cost of providing products to the required quality standards. The cost of non conformance (CONC) is the failure cost associated with process not being operated to the requirement.

\section{Discussion}

Since the TQM concept was built, this quality system was confirmed to be applied to improve the quality level of product or service, reduce the quality cost. The costs of quality are not just the cost of running quality 
department and the laboratory, plus rework, scrap and warranty cost, they are also the cost of designing, implementing, operating and maintaining a quality management system. The quality cost report can tell us which stage should be improved firstly. According to Dale (1999, P151), there are 4 categories uses of quality cost:

1) Promoting quality as a business parameter.

2) Giving rise to performance measures.

3) Providing the means of planning and controlling quality costs.

4) Acting as motivators.

It sounds like general management knowledge. All there usage can shows us how to reduce total costs. Dale and Plunkett also point out, (1990), quality cost may be reduced to one-third of their current level by the use of a cost effective quality management system. But we should invest first. Then get benefit from the good quality level. That means we can get low cost and high quality level at the same time. Why the good quality level comes with the low quality cost? We can use a quality cost model to analysis the relationship between the quality and cost. Let us look at a well-know model of the relationship between quality and cost, the standard Juran 'quality cost model'. It shows us how a company's quality costs are likely to change with changing quality levels is illustrated in figure 1.

As the figure shows, when the quality level is improved by more investment in prevention and appraisal process (curve2), the costs of failure fall dramatically (curve1). But beyond a certain point greater future investment will produce only moderate reduction in failure cost. The resultant total quality cost (curve3) will fall to the optimum cost lever $\mathrm{A}$, and then rising again as improvement instituted.

In TQM system, we put a little more investment in minimal part of total quality cost, prevention cost; get a big reduction of cost from main part of total quality cost, failure cost. Maybe the appraise cost will be reduced at the same time. In brief, most company consume the quality budget in an incorrect method. Most of money spends for dealing with the failure product and inspecting to avoid defect escape into market. In contrary, the money spends for prevention is less. Actually, only the prevention management can avoid a vicious circle of high quality cost but low quality level.

In the TQM system, according to this model, let us analysis how the quality cost change in detail. We raise the quality prevention budget to apply on the general management system. The product defect will decrease, that means the failure cost will be reduced. At the same time, the cost for the daily test and inspect activity can be lessened because the decrease of defect.

In the other hand, there are some problems in such a quality cost model. The most serious problem is that a key factor, TIME is ignored. As the Parker point out (1995), improvements in quality usually have latent benefits. These improvements need the cost such as new practices, training and capital investment in new equipments. These costs are therefore heavily toward the beginning of improvement period whereas the benefits are permanent each year over the product market lifecycle. It concludes than this quality cost models is also limited and incomplete.

The P-A-F model also has a big drawback. The prime function in TQM is prevention of defect or quality problem. But it very difficult to separate the prevention costs from the total budget. Every management cost to ensure quality may not be included into the quality costs. In a total quality system that focus on process rather than product. Therefore the so-called "process cost model" described in the revised British Standard 6143-1(1992) is a better method for applying quality to a company. It uses process modelling to simplify classification. According to the British Standard, the cost of quality has been separated into the cost of conformance $(\mathrm{COC})$ and the cost of non- conformance (CONC):

$$
\mathrm{COQ}=\mathrm{COC}+\mathrm{CONC}
$$

The cost of conformance (COC) is the process cost of providing products to the required quality standards. The cost of non conformance (CONC) is the failure cost associated with process not being operated to the requirement. Process cost model can be applied for any process in an organization. We can develop a flowcharting to identify the key process and the parameters that are monitored in the process. Sometime we use this model as a simple tool to measure the finance of a process. Actually it relates to the all management levels in the organization. The top manager should encourage the process improvement activities and give the employee awards when achievements have been done. Otherwise these activity will lost its function as the time pass. Only the TQM system is the platform to implement this model. It create the culture and provide the environment for continue improvement. 
Through the discussion above, it make sence that the quality cost system will bring us the benefit. In the other hand, there are many risks to apply this system. Firstly, it is very difficult to differentiate between the cost categories. Whatever model we apply, a lot of works need to be done to get this information. The decision is hard to be made if the data are incorrect. Secondly, we should be aware of that the whole cost reduction is the top priority. The competition between different departments to be a champion may be cost more than the entire saving. Costs may increase as team becomes better at identifying sources of and capturing data. Because this is a non value-add working. It is also be interpreted as quality deteriorating. Finally, it is most important that In TQM how can we justify a balance between failure (acceptable quality) and cost? In some theory, there is no cost barrier to continually improving quality. They consider loss to society as the biggest quality cost. This concept is more globe issue and it beyond the boundaries of the company. It is not appropriate that the company focus on the issue beyond themselves at the beginning of quality improvement. Business is a business. Except the safety issue, some quality problem is acceptable if it need a lot of money to fix.

\section{Conclusion}

The target of apply a quality system is to reduce the total quality cost to achieve the biggest profit. The relationship between quality and cost is very important for top manager to have a business decision-making. But every quality cost model is limited because of the complex nature of the problem that they face. Since we can see that each model has its advantage and disadvantage. We should make an analysis before we implement a model in our company. How to use these models is different in the different situation of individual organization. The company should develop a proper quality cost reduction programme. It is important than we should focus on how to achieve the cost-efficient quality and come to an acceptable quality level. We should treat the quality cost system as a worthy investment project and get the profit from it.

\section{References}

Dale, B. G. (1999). Managing Quality. - 3rd Ed.

Groocock, J.M. (1974). The Cost of Quality.

Oakland, J.S. (2003). Total quality management.

Parker, G.W. (1995). Achieving cost-efficient quality.

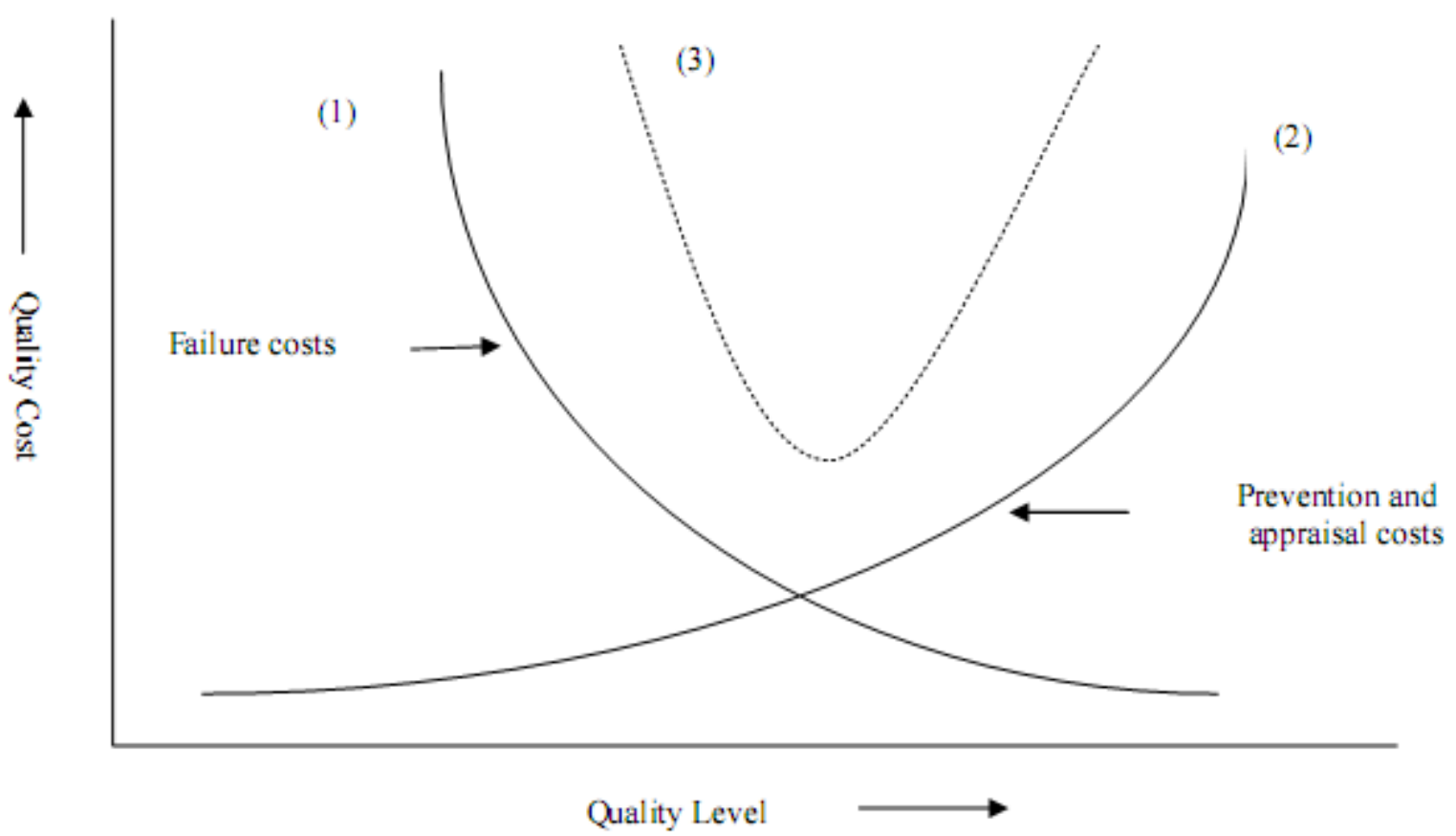

Figure 1. standard quality cost behaviour model (Parker, 1995, P10). 